1. Definições gènéricas:

2. Padrizes ronflitantes de comportrmento social:

3. Hedomismo no amsumo;

4. Dimensões ettras da hedonomia;

5. Propaganda hedonistica;

6. Amatiaçán da propagunda;

テ. Conchusion.

Alkerto de Ollieira Lima Filhu*

68

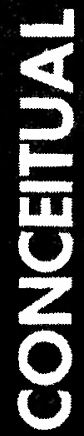

$\frac{u}{2}$

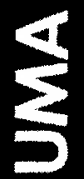

西

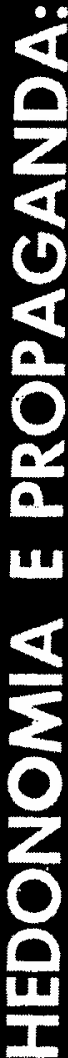

* Professor do Depaltamento de Mer. cadologia da Fscola de Arministracão de Empresas de são Pauk. da Funda(ä) Getulin barzen.

\section{Definições genéricas}

O hedonismo o urra teolia de comportamento que enfatiza, como critério central, o prazer. Para os hedonistas, o prazery pode assumir un amplo espectro, que vai deste prazeres puramente sensitivos ate sensaços de prazer espirituais e extre. mamente subjetivas, as quais podem ser derivadas da fama, reputaçäo, amizade ou simpatia.

A perspectiva hedonistica sustenta que os prazeres fisicos esensuais nầ săo efémeros, mas, ao contrário, são fausa e efeito de primeiros requi. sitos para a felicidade; portanto, ninguém pode desfrutar a vida o ser feliz sob dor ou outro tipo qualquer de condiçäo restritiva.

O hedonismo ó una palavira de origem grega, que significa literalmente: prazer (hedone). Os primeiros hedonistas foram os epicuristas, para quem beleza, estetica prazer apenas devem ser obtidos sob a orientaçáo dit razäo; portanto, para eles, o comportamento hedonistico estava muito próximo do lacional e não poderia ser rotulado romo um compontamento desiviado dos padrōes. Ionmais.

Mais tarde, Bentham continua a análise do hedonismo, ar Jongo das mesmas limhas, propondo rue cada individuo năo tem outra finalidade que () setu proprio praker": assim, fle diz: "Eu me comprito da mancira pela qual ou creio que terei maior prazer"."

Paía Bentham, a natureza colocou a espécic numana sib a dominio de dois mestles soberanos: dor a prazer.

So concoldarmos com tais assertivas, podemos extabelewer uma escala de felicidade diretamente relacionarla à escala de prazerp. Fistas escalas esfão, evidentemente. sujeitas a diferencas reletiVas e individuais, as quads estão sempre mudando de periodo a periodo.

Os niveis de racionalizaça e năo-racionaliza(a) do compertamentu hedonistico, pela mesma lahâo, sâo txtremmente diferenciados para grupes ou individuos na sociedade. Além disso. mes. mo a sociedade, derido a seus costumes e valoress, prode ou náo legitimar alguns padrỏes de herdonisimo.

Acreditamos que o comportamento promociomale de marketing tem um importante efeito sobre (1) tracos hedonisticos da sociedade moderna. O principal objetivo deste estudo é, portanto, examinar a natureza deste problema e estabelecer alsuns rriterios frata avaliar, de um ponto de vista etico,o impactio e o efeito da propaganda sobre o herdonisinu que i, afualmente, difundido e acei10 (m) latgin ('st"ilia entre os consumidores. 
A fim de atingir este objetivo, o assunto será tratado, na primeira parte deste trabalho, de uma perspectiva macroanalítica, e de uma perspectiva microanalítica, na segunda parte.

As conclusões pretendem conduzir o leitor a uma avaliação do hedonismo do ponto de vista racional.

\section{Padrões conflitantes de comportamento social}

A cultura ocidental moderna sempre foi sujeita a valores e costumes sociais de natureza conflitante. Partindo do Puritanismo e do Tradicionalismo, que são basicamente doutrinas fundamentadas em motivos econômicos e tradicionais, hoje em dia o analista é capaz de determinar contrastes flagrantes, se adotar uma posição retrospectiva. As áreas metropolitanas de países do mundo ocidental foram consideradas, por um moralista, como extremamente hedonisticas e orientadas por forças não significativas, em direção a objetivos materialistas $e$, frequientemente, sem nenhum valor intrínseco. ${ }^{2}$ A última década e o presente momento da cultura ocidental, evidentemente, mostram um profundo conflito entre hedonismo e puritanismo tradicional. No primeiro conjunto de valores, a finalidade precípua é a satisfação e gratificação dos consumidores por meio de uma extensa gama de produtos de luxo e sofisticados. No segundo, os temas centrais são a temperança, economia e emancipação de desejos materialísticos. ${ }^{3}$

Se a análise toma uma posição imparcial, pode-se determinar três diferentes periodos ao longo do desenvolvimento desse processo:

$1^{\circ}$ periodo: o puritanismo foi bom e adequado para incrementar a economia e o bem-estar na cultura ocidental;

$2^{\circ}$ periodo: o hedonismo e a economia de mercado estão levando a civilização ocidental a uma completa e amadurecida economia consumerística;

$3^{\circ}$ periodo: os padrões hedonísticos estão ameacando o sistema e alguns retrocessos em direção ao puritanismo seriam convenientes para a cultura ocidental.

O puritanismo e o tradicionalismo, os quais foram, sem dúvida, a tônica predominante da história econômica da civilização ocidental, devem ser avaliados como adequados aos objetivos econômicos do Renascimento e pré-revolução industrial; a busca da moderação dos costumes, a racionalização de necessidades e desejos, o orgulho pelo trabalho e o respeito aos objetivos comunitários foram, certamente, a única e verdadeira razão que explica o sólido e contínuo crescimento de nações como Inglaterra, França, Alemanha e EUA. A motivação de consumo era orientada para objetivos conservadores e não sofisticados, os quais deram lugar a uma hierarquia ortodoxa no consumo e aceitação do produto.

Estes traços mantêm-se ainda firmes nas características antropológicas das culturas anglo-saxônica e latina. Em produtos domésticos, por exemplo, a propaganda ainda continua usando apelos econômicos e racionais.

Os padrões hedonísticos, como características importantes e difundidas, aparecem mais tarde na cultura ocidental, e são mais um resultado do avanço tecnológico e um produto do conjunto de valores urbanos.

Durante esse periodo, e até o presente, a legitimação do lazer, a busca do sensual, das recompensas estéticas e psicológicas tornam-se aparentes e amplamente aceitas.

A tendência nesse sentido, certamente, teve inicio entre os membros da classe de rendimentos altos. Dentre as inúmeras condições que possibilitaram tais mudanças, podem ser mencionadas: aumento de rendas discricionárias, decréscimo de lealdade para com a Igreja, modernização e comunicação em massa. Os primeiros a adotarem atitudes genericamente hedonisticas foram, portanto, membros da alta sociedade, os quais possuiam, pelas mesmas razões, segurança suficiente para consumir em altos padrōes e estabelecer estilos de consumo.

Os estudos de Pierre Martineau, Lloyd Warner e Wroe Alderson explicam como individuos pertencentes a classe alta agiam como geradores de um novo estilo de vida para todas as outras classes da sociedade. ${ }^{4}$

Seguindo o novo comportamento hedonistico e, em virtude de um processo de adaptação, emulação e assimilação, outras classes sociais rejeitam a idéia de que tais atitudes e valores consumerísticos não eram mais do que formas aparentes e vulgares de ostentação.

O sistema de marketing imediatamente se aproveitou destas condiçōes permissivas, porque elas estavam em perfeita compatibilidade com as regras de produção e de consumo em massa.

A fim de sustentar o acréscimo no consumo de produtos hedonísticos e de luxo, a propaganda seguiu a mesma trilha com as mais proveitosas contribuições para esta revolução nos padrões de comportamento dos consumidores.

O final dos anos 60 e começo dos 70 são representativos de uma interessante dicotomia de valores; os dias atuais são marcados por dois tipos de grupos hedonísticos: o primeiro grupo que ainda está voltado ao bem-estar material e continua com a mesma maneira de viver, consumindo bens duráveis de alto custo, novidades e mercadorias de etiquetas exclusivas; o segundo grupo, na maio- 
ria os "não-conformistas" da nova geração, apelam para o hedonismo, procurando romper com os padrões formais da sociedade. Os membros deste grupo rejeitam os bens materiais para atingir suas metas de vida; assim sendo, a liberdade transforma-se no alvo básico e principal de suas aspirações.

Portanto, conflito de valores e de atitude sociais trazem disfunções ao sistema e requerem uma reavaliação das dimensões éticas do mesmo, em termos de urgência, uma vez que a felicidade coletiva está desaparecendo e a tristeza aumentando assustadoramente.

Se é certo que os mercadólogos devem assumir uma posição ética e racional, com relação ao problema, torna-se necessário fazer uma análise objetiva da orientação básica que os sistemas econômicos capitalistas e neocapitalistas deram à utilização dos recursos econômicos. Ereciso ainda entrar na consideração dos efeitos da tecnologia sobre os padrões de vida que os grupos humanos desfrutam na atual década.

E fácil perceber que a manutenção de padrões de consumo, nos quais seja possível o uso de telecomunicação, de energia elétrica, de transporte rápido a longa distância, de medicina socializada, exige que os recursos econômicos sejam utilizados de maneira eficiente; de modo muito especial, o trabalho precisa continuar legitimado, as economias de escala necessitam ser atingidas, e o consumo em massa deve ser incentivado. ti somente neste contexto que a escassez típica dos periodos de consumo restrito poderá desaparecer gradativamente.

Entretanto, nota-se atualmente uma atitude ambigua no que se refere à liberdade de consumo, em contrapartida à liberdade de produzir e incentivar o consumo.

Os críticos do sistema de marketing e da propaganda insistem em fazer ataques drásticos às duas atividades, afirmando que a primeira tem características ultramaterialistas, enquanto que a segunda poderia gerar uma multidão de consumidores sem orientação própria, conformista e com a liberdade de escolha totalmente anulada. ${ }^{5}$

$O$ primeiro conjunto de críticas não encontra uma sustentação muito sólida, principalmente se levarmos em conta que as atividades do marketing são primordialmente destinadas a servir e obter a demanda, e mais ainda, se considerarmos o fato de que quanto mais eficiente for o nivel de desempenho de um sistema de marketing, tanto maior será a variedade de produtos e serviços ofertados. Desta maneira, aqueles que não quiserem consumir em alto estilo, por convicções individuais ou antimaterialistas, poderão simplesmente comprar produtos para mantê-los em nível modesto e sem nenhuma característica de sofisticação.

Ao segundo conjunto de críticas bastaria uma resposta simples sugerida por Alderson; segundo este autor, a função da propaganda é um composto de elementos informativos e persuasivos; ambos os elementos servem como ingredientes catalisadores do processo decisório de compra, dependendo a solução final das características de racionalidade e não-racionalidade do próprio consumidor.

De um ponto de vista mais genérico, os críticos de propaganda afirmam que seu efeito sobre os consumidores tem características de "plasticidade", ou seja, criam uma mudança de comportamento quase que permanente em certos segmentos de mercado. ${ }^{6}$

Entretanto, como um resumo da análise anterior, pode-se afirmar que ambos segmentos da sociedade, ou seja, os tradicionalistas e os modernistas, os materialistas e os espiritualistas, os conservadores e os renovadores, procuram no consumo uma forma hedonística de sofisticação dos seus desejos e necessidades.

Para atingir tal "estado de natureza", que é inerente à real complexidade do sistema, Alderson propõe que empresas, e mais especificamente marketing, deveriam iniciar a difusão de um novo tipo de abordagem, chamada hedonomia. ${ }^{7}$

À primeira vista, o significado de hedonomia pode ser simplesmente definido como ... aplicação dos instrumentais e recursos de marketing ao desenvolvimento da maximização de prazer individual, levando-se em conta que muito poucas pessoas podem atingir o prazer máximo por si sós...

Na realização desta tarefa, o marketing representa $o$ instrumental, e a propaganda, a força catalisadora. Se esta linha de raciocínio for considerada correta, a propaganda tem um papel de destaque no desenvolvimento de condições para tornar operante o processo hedonístico, uma vez que irá prover informação, persuasão e conhecimento, relativamente às ações competitivas.

Neste caso, a propaganda terá três dimensões básicas:

1. Informativa: que dá as informações necessárias sobre o produto, a satisfação do que se pode oferecer ao consumidor hedonístico;

2. Persuasiva: que dá ênfase ao uso de bens materiais para que o consumidor se aproxime do nível ótimo de satisfação hedonista;

3. Competitiva: que reduz a incerteza, atentando para diferentes aspectos das marcas e dos produtos. ${ }^{8}$

As três dimensões descritas estão aptas a prover uma boa base para os objetivos da hedonomia. 
Assim, os consumidores estarão aptos a superar confusões, a se tornarem mais racionais, alcançando maior liberdade no processo de escolha.

O poder da hedonomia deve, também, ser usado apropriadamente pelas empresas, as quais visam à maximização do lucro a longo prazo.

Tal perspectiva deve ser concebida com uma utilização racional do poder do marketing $e d a$ propaganda, considerando-se que as empresas devem usar seus recursos de maneira correta a fim de incrementarem a satisfação, prazer e felicidade do consumidor.

Do ponto de vista dos consumidores, a hedonomia é útil para melhorar a eficiência das tarefas de fazer compras, é útil também para aumentar a escala de satisfação que os mesmos, por si sós, não seriam capazes de alcançar sem a orientação sólida e adequada de propaganda, as quais são o ponto de apoio da perspectiva hedonômica.

\section{Hedonismo no consumo}

Parece ser bastante difícil encontrar um produto ou classe de produtos, no amplo conjunto de grandes ofertas proporcionadas pela indústria moderna, que não represente a característica hedonística em suas dimensões. Todos os produtos, certamente, são em última instância vendidos ao consumidor e por ele aceitos, devido à sua capacidade própria de prover satisfação. O processo de compra é multidimensional e inclui aspectos funcionais estéticos, sociais e psicológicos. ${ }^{9}$ Quase todos os aspectos do conceito de produto total incluem aspectos hedonísticos, uma vez que os consumidores querem a satisfação de suas necessidades e desejos, os quais, em outras palavras, são o aumento dos prazeres hedonisticos, tais como felicidade, altruísmo, conforto, orgulho, amizade e assim por diante. ${ }^{10}$

Uma vez que necessidades e desejos são geradores de padrões de comportamento, os quais provêm recompensas, é fácil compreender que muitas das atitudes do consumidor estão diretamente relacionadas à aquisição de recompensas, as quais são por sua própria natureza hedonísticas.

Diferentes indivíduos percebem o prazer de uma perspectiva ampla e heterogênea, mas de uma maneira geral, a escolha de compra, preferências de marca e outros padrões de consumo são relativos ao conceito de satisfação individual. Os consumeristas usam mais de decisões emocionais, para instrumentar o seu comportamento de compra. Exemplos:

a) satisfação dos sentidos: perfumes, desodorantes, sabonetes, xampu, música, comidas especiais, ar condicionado etc.; b) preservação de espécie: seguros, ações, investimento etc.;

c) descanso e recreação: esportes, camping, viagens, leitura, TV ou música;

d) medo: remédios, vitaminas, serviços de segurança da casa, exame físico geral etc.;

e) orgulho: sabonetes, escovas de dentes, máquinas de lavar roupa, cosméticos;

f) sociabilidade: pertencer a clubes e organizações, coquetéis, grupos com atividades esportivas etc. ${ }^{11}$

Entretanto, os individuos econômicos, por sua vez, desenvolvem seu critério de escolha; em função de outro conjunto de motivações, que podem levar a padrões de consumo conservadores. Porém, este comportamento é, da mesma maneira, conduzido por recompensas de sua própria motivação. Em ambos os casos, o analista está apto a perceber que o hedonismo, ou a rejeição de situações desagradáveis, está presente em todas as decisões de consumo.

\section{Dimensões éticas da hedơ̌homia}

O fundamento básico da hedonomia, estabelecido por Wroe Alderson, presume um nível ideal de comportamento ético, no sentido de tornar esta perspectiva aceitável socialmente. Alderson sustenta também que as mudanças de gosto e preferências são desenvolvidas dentro de certa ordem, as quais estamos preparados para suportar e queremos que se efetue, em qualquer nível de renda. ${ }^{12}$ Portanto, é verdade que a hedonomia não pode ser prejudicial ao bem-estar do consumidor. Alderson crê também que a hedonomia pode, isto sim, diminuir a extensão das mudanças causadas pela propaganda, pois ela pode reduzir o desperdício nas compras, as quais, por outro lado, não estariam sujeitas a um objetivo processo de escolha.

A hedonomia também aumenta a sensibilidade do consumidor, levando-o a estar mais atento para a exata qualidade e desempenho dos produtos que compra e usa.

Nos aspectos aqui analisados pode-se chegar a conclusão de que a propaganda, como um instrumental da hedonomia, pode ser desempenhada dentro de padrões altamente éticos, uma vez que aumenta a capacidade de satisfação individual e, o que é mais importante, enfatiza a habilidade de escolha do consumidor.

Para alcançar o estágio no qual a hedonomia tenha um nível desejável de ética, instrumentos e práticas corretas de propaganda são evidentemen. te desejáveis; entretanto, de uma maneira geral, a propaganda pode prover os seguintes fatores: 
a) aumentar o grau de escolha, ao invés de diminuí-lo;

b) permitir um nivel de informação adequado, que possibilite a redução da dissonância cognitiva; ${ }^{13}$

c) eliminar as limitações do consumidor no que se refere à avaliação de produtos em relação a seus objetivos pessoais e a seu pragmatismo.

O somatório das qualidades mencionadas são valores ideais e positivos de um sistema de livre mercado, que por sua vez repousa em uma hierarquia de valores tais como serviços ao consumidor, desenvolvimento individual e comunitário, liberdade de escolha, além do objetivo tradicional da maximização dos lucros. ${ }^{14}$

A ética hedonômica é em essência normativa, pois seu objetivo central é estabelecer normas para a conduta individual e também das empresas, no que concerne à ação administrativa e ao processo decisório. A hedonomia também se relaciona com os traços materialísticos de nossa sociedade, a qual empresta uma ênfase substancial à aquisição de bens materiais. Por isso, é certo afirmar que a filosofia básica da hedonomia parte da premissa de que seus objetivos são destinados a servir valores sociais aceitos, e não a impor mudanças em práticas de negócio aceitas e em padrões éticos já reconhecidos.

\section{Propaganda hedonística}

A grande maioria dos apelos de propagand: orientada para o aumento do prazer, para a redução das tensões, e para suplantar ansiedades e insegurança individual. As linhas gerais dos textos e das mensagens são de certa forma compativeis com a tendência orientadora do comportamento hedonístico, o qual é uma característica inerente à sociedade contemporânea.

Folheando uma revista e avaliando anúncios para diferentes tipos de produtos ou para diversos segmentos de mercado, é muito difícil encontrar-

72 mos um anúncio que não apresente alguma dimensão hedonística.

Vejamos, por exemplo, alguns anúncios recentemente publicados:

a) um anúncio para mobiliário de cozinha promove qualidades tais como limpeza, cores, espaço, facilidade de manuseio etc.;

b) um anúncio de fumo para cachimbo diz: "Nós criamos um aroma para o nosso tabaco, sabendo que as mulheres não fumam cachimbo... mas que elas permanecem muito próximas en. quanto você fuma..., que elas ficam muito meigas..., que elas adoram sentir que você tem um perfume de homem..."; c) um anúncio para lençóis e roupas de cama apresenta a seguinte mensagem: ". . a noite é um periodo extremamente longo, no qual você se mexe, você sonha, você acorda e às vezes também faz outras coisas. ...;

d) a perua VW Variant diz em seu anúncio que "o espaço interno é tão amplo que em certas ocasiões até é possivel deitar-se";

e) um anúncio de loção de barba tem a seguinte mensagem: "finalmente... encontramos um produto que combina com a sua barba, com a sua lavanda, com seu Porshe, e com o seu estilo de vida...";

f) as sopas Maggi em seu anúncio dizem: "Maggi é a certeza de sabor e qualidade. . ." 15

Apesar do conteúdo fortemente hedonístico desses anúncios, ninguém, com base racional, pode afirmar que eles reduzem a capacidade racional de julgamento, restringem a capacidade de exercer livre escolha dentre outras alternativas, ou mesmo induzem a qualquer tipo de comportamento prejudicial.

Ao contrário, as idéias intensas e pragmáticas desses anúncios estão sintonizadas com novos padrões de vida, objetivos e racionais; com elementos estéticos que regem padrões da sociedade moderna, e também nada têm contra normas morais já amplamente aceitas no meio social cosmopolita dos grandes centros urbanos.

\section{Avaliação da propaganda}

O conceito de ideologia, que é simplesmente defì. nido pela conceituação individual do modo de vida ou do sistema social que o indivíduo elege para si próprio, ${ }^{16}$ serve como um modulo adequado para avaliar as dimensões nedonísticas da propaganda.

Se a propaganda não fosse hedonística, ela simplesmente seria ajustada pela sociedade e por grupos desta sociedade que apresentassem ideologias hedonísticas; esta abordagem e também suas perspectivas, longe de serem conservadoras ou radicais, não estabelecem critérios preestabelecidos de julgamento entre fraco e forte, entre certo e errado; bem ao contrário, esta ideologia permite uma amplitude de opção individual associada a um substancial estímulo à escolha mediante autodeterminação.

A propaganda hedonística, como instrumento básico da hedonomia, deve ser julgada como uma ideologia liberal, progressista, muito adaptável, pragmática e racional.

Em conclusão, a utilização e a aceitação da característica hedonística da propaganda trazem mais beneficios do que prejuizos ao consumidor, e, em última análise, à própria sociedade, sim- 
plesmente porque possibilitam melhor informação, melhores opções de escolha, mais recompensas de caráter interno em períodos nos quais muito poucos sabem exatamente como será o futuro.

As dimensões do sistema econômico de livre empresa baseiam-se na premissa de que decisões livres e inteligentes devem necessariamente ocorrer no mercado de consumo. De certa forma, uma extensão deste raciocínio indica também sua compatibilidade com as regras centrais da hedonomia mediante as quais todos os consumidores devem ser informados sobre inovações, nivel de tecnologia, disponibilidade de produtos, alternativas de venda etc.

Para executar estas tarefas, nota-se que a propaganda é o instrumento efetivo, eficiente e liberal, que ao mesmo tempo deve ser julgado como o mais importante suporte para o desenvolvimento do processo hedonômico.

\section{Conclusão}

O principal objetivo deste estudo foi estabelecer, analisar e avaliar as relaçōes entre hedono. mia e propaganda.

O processo de avaliação leva-nos à conclusão de que a hedonomia pode ser aceita em decorrência de sua compatibilidade com os valores da nossa sociedade e que a propaganda desempenha um papel preponderante na efetivação do processo hedonômico.

Da mesma maneira, a propaganda é adequada para reforçar idéias, estimular informações e aumentar padrões discricionários de escolha.

\section{REFERENCIAS BIBLIOGRAFICAS}

Alderson, Wroe. Men motives and markets. New Jersey, Prentice Hall, 1968.

-.Marketing behavior and executive action. Homewood, Ill., Irwin, 1957.

- Ethics, ideologies and sanctions. AMA, Dec. 1964. Report of the Committee on Ethical Standards and Professional Practices.

Bentham, Jeremy. The rationale of reward. 1825; The rationale of punishment, 1830. (Arquivos da Biblioteca do Congresso).

Bishop, F. P. The ethics of advertising. London, Hale , Ltd, 1962.

Boyd, Harper \& Levy, Sidney. New dimensions in con. sumer analysis. Harvard Business Review, Nov./Dec. 1963.

Finkelstein, Louis. The businessman's morale failure. Frortune. Sep. 1964.

Hammond III, John. Preference theory. Harvard Bu siness Review, Boston, Nov./Dec. 1968.
Kelley, Eugene. Marketing: a mature discipline. Dec. 1960. Proceedings of the Winter Conference of AMA.

Kleppner, Otto. Where does advertising fit in. New York, AMA, 1952.

McCarthy, E. Jerome. Basic marketing, a managerial approach. 3 ed. Homewood, Ill., Irwin, 1968.

Martineau, Pierre. The pattern of social classes. In: Clewett, R. L. ed. Marketing role in scientific management. Chicago, AMA, 1957.

Nicosia, Francisco. Consumer decision process. Engle. wood Cliffs, N. J., Prentice-Hall, 1966.

1 Bentham, Jeremy. The racionale of reward. 1825: The rationale of punishment. 1830. (Arquivos da Biblioteca do Congresso).

2 Finkelstein, Louis. The businessman's morale failure. Fortune, Sep. 1964. p. 114.

3 Kleppner, Otto. Where does advertising fit in. New York, AMA, 1952. p. 17.

4 Alderson, Wroe, Men, motives and markets. New Jersey, Prentice-Hall, 1968. p. 43-54. Veja também: Mar. tineau, Pierre. The pattern of social classes. In: Clewett, R. L. ed. Marketing role in scientific management Chicago, AMA, 1957. p. 233-49.

5 Alderson, Wroe \& Halbert, Michael H. Men, motives and markets. Englewood Cliffs, New Jersey, Prentice-Hall, 1968. p. 24-5.

6 Alderson, Wroe. Marketing behavior and executive action. Homewood, Ill., Irwin, 1957. p. 277.

7 Id. ibid. p. 287. Obs.: Alderson compara o novo termo hedonomia com economia, pela simples razão de que hedonomia, de maneira similar à economia, tem como objetivo primordial a utilização de recursos para administrar e maximizar o prazer.

8 Bishop, F. P. The ethics of advertising. London, Hale, Ltd., 1962. p. 34.

- McCarty, E. Jerome. Basic marketing - a managerial approach. 3 ed. Homewood, Ill., Irwin, 1968. p. 203.

10 Boyd, Harper \& Levy, Sidney. New dimensions in consumer analysis, Harvard Business Review, Nov./Dec. 1963. p. $129-40$.

11 Nicosia, Francisco. Consumer decision process. Englewood Cliffs, N. J., Prentice, 1966. p. 41.

12 Alderson, Wroe. op. cit. p. 102.

13 Nota do autor: dissonância cognitiva é o estado psicológico desenvolvido por pessoas que, após adquirirem um produto, sentem-se inseguras quanto à validade da compra e buscam portanto razóes de natureza subje. tiva e/ou informaçóes adicionais para reduzir este estado de tensão psicológica. A Teoria de Dissonância Cognitiva foi testada por Leon Festinger em Stanford. 14 Kelly, Eugene. Marketing: a mature discipline. Chicago, Ill., Dec. 1960 . p. 195-203. Proceedings of the Winter Conference of AMA.

15 Exemplos retirados de anúncios publicados em revistas recentes dos Estados Unidos.

16 Alderson, Wroe. Ethics, ideologies and sanctions. Committee on Ethical Standards and Professional Prac. tices, AMA, 1964. p. 1-20. Report (năo publicado). 